This is an unedited manuscript in press in the Career Developmen Quarterly

Please note that the published version will undergo minor additional editing in style and content.

Complete reference:

Hirschi, A., \& Valero, D. (in press). Chance Events and Career Decidedness: Latent Profiles in Relation to Work Motivation.

Career Development Quarterly.

\title{
Chance Events and Career Decidedness: Latent Profiles in Relation to Work Motivation
}

\author{
Andreas Hirschi* and Domingo Valero ${ }^{\mathrm{a}}$ \\ University of Bern, Switzerland
}

\author{
*Corresponding author: University of Bern, Institute of Psychology, Fabrikstrasse 8, CH-3012 Bern, Switzerland; \\ Tel. +4131631 86 07; Fax +413163182 12; e-mail: andreas.hirschi@psy.unibe.ch \\ aUniversity of Bern, Institute of Psychology, Fabrikstrasse 8, CH-3012 Bern, Switzerland; \\ Tel.+41 3163134 17; Fax+41 3163182 12; e-mail: domingo.valero@psy.unibe.ch
}

Acknowledgement. The authors were supported by Grant 140279 (Project "The motivational system of career choices: Effects on choice implementation and career success") from the Swiss National Science Foundation. The funding source had no involvement in study design, in the collection, analysis and interpretation of data, in the writing of the report, or in the decision to submit the article for publication.

\begin{abstract}
Research has shown that chance events affect careers but has not established the nature of their effects. Moreover, the relationship between chance and career decidedness is not well understood. The present study used a person-centered approach with latent profile analysis to examine 312 Swiss adolescents in their first year of vocational training. We identified five qualitatively differing profiles according to levels of perceived chance events and career decidedness: balanced scorers, undecided with mean chance, undecided with high chance, decided with chance, and decided without chance. The groups differed significantly in work motivation (i.e., occupational self-efficacy beliefs, perceived person-job fit, and work engagement). Decided adolescents reported more favorable work motivation regardless of their level of perceived chance events. The results imply that promoting decidedness remains a valuable goal in career counseling despite the occurrence of unpredicted events.
\end{abstract}

Keywords: chance events; work motivation; career decidedness; adolescents; 


\section{Introduction}

Empirical research suggests that many people have experienced (multiple) chance events in their career development and that chance events have impacted their career decision making (Bright, Pryor, Chan, \& Rijanto, 2009; Bright, Pryor, \& Harpham, 2005; Bright, Pryor, Wilkenfeld, \& Earl, 2005; Hirschi, 2010; Williams et al., 1998). Other research has attempted to identify factors that affect the perception of and perceived effects of chance events. These studies have suggested that internal characteristics such as locus-of-control beliefs, selfconfidence, and openness to experience as well as external factors such as barriers and social support are important in this regard (Bright, Pryor, \& Harpham, 2005; Hirschi, 2010; Williams et al., 1998).

However, the relationship between chance events and career decidedness remains largely unexplored. Theoretically, this relationship is important because being open to unexpected opportunities and taking advantage of chance events is often depicted as the opposite of the more traditional focus in career development and counseling, which stresses the importance of being clearly decided regarding one's career (Krumboltz, 2009; Mitchell, Levin, \& Krumboltz, 1999). Yet, we are aware of only one empirical study that explored the relationship between career decidedness and perceived chance events. Examining two samples of Swiss adolescents, Hirschi (2010) showed that perceived influence of chance events was not significantly related to career decidedness and career planning beyond demographic and personality factors. In the present study, we applied a person-centered approach to explore the relationship between perceived chance events and career decidedness. Such an approach takes into account that several subgroups that show distinct combinations (profiles) of perceived chance events and levels of career decidedness might exist within a population. Conversely, a variable-centered approach explores the on-average relationships between variables within a given sample from a population. We believe that a person-centered approach is particularly meaningful in exploring the relationship between chance events and decidedness because it is plausible that chance events have affected the careers even of some people with clear career plans and a selected career path. For others, chance events might have been influential while they were open to different possibilities and highly undecided regarding their career. As such, the onaverage relationship between chance and decidedness might not be very meaningful in understanding the true relationship between these two factors. In fact, different combinations (profiles) of chance and decidedness across groups of people would remain undetected when using a variablecentered approach focusing on the on-average relationship between chance and decidedness.

\section{Are Chance Events Good or Bad?}

According to Happenstance Learning Theory (HLT; Krumboltz, 2009; Krumboltz, Foley, \& Cotter, 2013) chance events might provide opportunities for objective and subjective success. HLT therefore urges career counselors to help clients to capitalize on chance events and actively incorporate the discussion of chance events into the career counseling process (Krumboltz et al., 2013; Mitchell et al., 1999). However, it is also possible that a job obtained based on chance events might lead to negative outcomes, such as less commitment in or engagement at work, because the individual was not able to realize his or her original aspiration. Yet, surprisingly, the questions of if and when chance events have positive or negative effects have rarely been explored empirically. Hirschi (2010) found that perceived chance events were significantly related to wish correspondence of and satisfaction with current training/education among Swiss adolescents in vocational training and high school, beyond the effects of sociodemographics, personality, and career decidedness and planning. However, some forms of chance events showed a positive relationship while others exhibited a negative relationship with the outcomes. In a study of 
managers in Israel, Grimland, Vigoda-Gadot, and Baruch (2011) found that those who reported that a fundamental chance event had affected their careers were in a higher position in their organization but did not report significant differences in career satisfaction or professional vitality compared to managers who did not experience such an event.

\section{Chance Events and Work Motivation}

In the present study, we extended these initial findings and focused on the relationship between perceived chance events and work motivation among adolescents in vocational training. Specifically, we investigated work motivation in terms of occupational self-efficacy beliefs, perceived personjob fit, and work engagement. These three variables are indicative of individuals' readiness to put effort into their work and to identify with it. Thus, these variables can be used to obtain a broad conceptualization of work-related motivation. Occupational self-efficacy beliefs refer to an individual's expectation that he or she can successfully fulfill work-related tasks (Rigotti, Schyns, \& Mohr, 2008). Self-efficacy beliefs influence which goals an individual chooses to pursue, the degree to which these goals are challenging, the effort an individual puts into achieving these goals, how an individual reacts to obstacles, and whether these obstacles are perceived as encouraging or demoralizing (Bandura, 2001). Supporting the importance of self-efficacy in the work context, one study showed, for example, that adolescents aged 12 to 15 with high self-efficacy beliefs reported less unemployment and higher job satisfaction at age 21 (Pinquart, Juang, \& Silbereisen, 2003). Perceived person-job fit refers to an individual's perception that his/her job is in line with his/her knowledge and abilities, needs, and vocational aspirations. Research has shown that person-job fit is related to employees' positive organizational attitudes (e.g., organizational commitment) and job attitudes (e.g., job satisfaction) (Saks \& Ashforth, 2002). Finally, work engagement refers to the experience of vigor, dedication, and absorption in one's work (Schaufeli, Bakker, \& Salanova, 2006) and is related to greater work resources and competencies in young employees (Akkermans, Schaufeli, Brenninkmeijer, \& Blonk, 2013).

\section{The Present Study}

When investigating the effects of chance events it is important to explore samples and contexts that are particularly suited to derive valuable insights in this regard. This is because, as the developmentalcontextual perspective on career development suggests, both the person and the context, including their interactions, must be taken into account when investigating career development (Hartung, Porfeli, \& Vondracek, 2005). Our study focused on adolescents, who are usually considered to be in an exploration phase where being curious, inquisitive, and openminded is important. However, at the same time, adolescents should continue to develop a sense of control, self-direction, and ownership of their lifecareers (Hartung et al., 2005). This implies that issues of chance like open-mindedness and exploration as well as issues of decidedness such as control and ownership are critical in this career stage.

We conducted the current study in Switzerland, where approximately $70 \%$ of adolescents begin one of over 200 types of vocational education and training after compulsory school (State Secretariat for Education Research and Innovation, 2014). Apprenticeship positions are announced by organizations and are awarded on a competitive basis to students who apply for them. The apprentices are then trained in successively complex tasks of the profession for the next two to four years - depending on the complexity of the occupation. During this time, adolescents work three to four days per week in their apprenticeship firm and spend one to two days per week in vocational schools for their theoretical education. Chance and decidedness are two important factors in this transition from school to vocational education and training. During the last two years of compulsory school, teachers and career 
counselors help to increase career choice readiness by fostering students' knowledge and decidedness regarding the world of work. Chance is also relevant because apprenticeship positions are awarded on a competitive basis based on interviews and work samples, similar to the ordinary job market. Chance events are thus a partial determinant of which profession these adolescents choose and what position they obtain. For example, chance encounters or hearing of a specific job can influence which profession piques an adolescent's interest. Knowing people in specific organizations or searching for open positions in a specific media outlet at a specific time can influence which open position attracts an adolescent's attention. For these reasons, the Swiss educational context and this first transition from school to work represent an ideal setting for investigating the interplay of chance events and decidedness and the relationship between these factors and work motivation.

In contrast to the cited variable-centered studies that explored the relationship between chance events and career outcomes, we herein apply a personcentered approach. Based on the above-described assumption that several subgroups with different combinations of perceived chance events and levels of career decidedness might exist within a population, we explored the extent to which people with different profiles differ in their work motivation. People with different profiles can differ quantitatively and/or qualitatively in their levels of chance and decidedness (Wang \& Hanges, 2011). Quantitative differences refer to the level of perceived chance events and career decidedness across groups, such as different groups showing generally lower or higher values on these variables. Qualitative differences refer to the shape of the profiles, with different groups showing different combinations of higher versus lower values on perceived chance events and decidedness. By exploring such group differences, the present analytical approach extends beyond analyzing mere correlations (or regression coefficients) between work motivation and perceived chance events. While such results can indicate how chance events are related to work motivation on average within a sample, our chosen person-centered approach allows us to establish whether different groups of people (according to their chance/decidedness profiles) show meaningful differences in work motivation. Such an analysis takes into account that nonlinear effects might occur and that the relationship between work motivation and chance events may differ across people, specifically, depending on the combination of chance and level of decidedness. However, the herein applied person-centered approach also extends beyond examining mere interaction effects of chance events and career decidedness. Interaction effects can be used in variable-centered analyses to estimate the combined effect of variables on outcomes. However, such analyses may fail to detect the existence of subgroups with distinct effects, particularly if these groups are small (Wang \& Hanges, 2011). Specifically, we examined the following two research questions.

Research Question 1: Are there quantitatively and qualitatively different profiles of perceived chance events and career decidedness?

Research Question 2: Are there significant differences between people with distinct chance/decidedness profiles regarding work motivation in terms of (a) occupational self-efficacy beliefs, (b) perceived personjob fit, and (c) work engagement?

\section{Methods}

\section{Participants and Procedure}

We contacted 17 schools of vocational education and training in German-speaking Switzerland and asked if they were willing to participate in our study of apprentices in their first year of training. Ten schools (59\%) agreed to participate. Data collection took place online during regular class hours in the schools' computer room. Participants were supervised by a teacher and were free to decline participation. We surveyed 312 students (119 girls, 193 boys) with a mean age of 17.92 years $(S D=1.92)$. The majority (53\%) of participants were of native 
Swiss origin, $31 \%$ had migrant backgrounds, the remaining 16\% indicated dual citizenship or did not indicate their nationality. Participants were trained in 26 different apprenticeships, most commonly nursing (18\%), plastering (10\%), professional housekeeping (10\%), and sales clerking (7\%).

\section{Measures}

Chance events. The degree to which one's career choice was experienced as influenced by different chance events was assessed with the following nine items from Bright, Pryor, and Harpham (2005): (i) professional or personal relationships (e.g., leading to information about jobs, recommendations, job offers); (ii) being at the right place/right time; (iii) encouragement from others (e.g., encouragement to attain education and experience, set higher goals, or pursue a new field); (iv) previous work/volunteer experiences; (v) obstacles in original career path; (vi) unintended exposure to a type of work or activity that was interesting; (vii) unintended exposure to a type of work or activity that was not interesting; (viii) unexpected personal event (e.g., injury or health problem); and (ix) other unexpected events. These events were rated on a scale from 1 (no influence at all) to 4 (great influence). Alpha reliability in our sample reached .72, similar to the value of .66 reported by the measure's authors (Bright, Pryor, \& Harpham, 2005). Previous studies that administered this measure showed that the perception of events was related to considering one's vocational choice as more incongruent with one's originally aspired career (Hirschi, 2010) and to an external control orientation (Bright, Pryor, \& Harpham, 2005).

Career decidedness. We used the seven-item German adaptation of the Vocational Identity Scale of My Vocational Situation (Holland, Daiger, \& Power, 1980; Jörin, Stoll, Bergmann, \& Eder, 2003). A sample item is "I'm not sure yet which occupations I could perform successfully", and answers were given on a rating scale from 1 (does not apply) to 5 (fully applies). All items were recoded to reflect positive career decidedness in this study. Reliability reached.87 in our sample, .86 was reported in an early study (Holland, Gottfredson, \& Power, 1980). The scale showed consistent relations with other measures of career planning and career exploration in samples of adolescents (Hirschi \& Herrmann, 2013).

Occupational self-efficacy. Occupational selfefficacy beliefs were assessed with six items (e.g., "I feel prepared for most of the demands in my job") from the German short occupational self-efficacy scale (Rigotti et al., 2008). Answers were given on a rating scale from 1 (not at all true) to 6 (completely true). The alpha in our sample (.78) was slightly lower than reported by the scale authors (.87; Rigotti et al., 2008). This scale showed positive relationships with job satisfaction, performance, and organizational commitment among working adults (Rigotti et al., 2008).

Person-job fit. Person-job fit was assessed with the four-item (e.g., "To what extent do your knowledge, skills, and abilities match the requirements of the job?") scale by Saks and Ashforth (2002). Participants rated the items on a scale from 1 (to a very little extent) to 5 (to a very large extent). The scale reached an alpha of .82 , similar to the values of .86 and .87 reported by Saks and Ashforth (2002). The scale was related to perceived work meaningfulness, work engagement, and occupational identity in a sample of German students (Hirschi, 2012).

Work engagement. We applied the short Utrecht work engagement scale (Schaufeli et al., 2006). The scale consists of nine items (e.g., "When I get up in the morning, I feel like going to work") that are assessed on a rating scale from 0 (never) to 6 (always - every day). The scale reached and alpha of .94 , slightly above the values between .85 and .92 reported by the scale authors (Schaufeli et al., 2006). Work engagement was related to a series of work-related competencies (e.g., work exploration, career control) among young Dutch employees (Akkermans et al., 2013). 
Table 1

Means, Standard Deviations, Cronbach's Alpha, and Intercorrelations of the Study Variables

\begin{tabular}{lllllllll}
\hline & $M$ & $S D$ & $\alpha$ & 1 & 2 & 3 & 4 \\
\hline 1 & Chance events & 2.22 & 0.50 & .72 & - & & & \\
2 & Decidedness & 3.66 & 0.84 & .87 & -.10 & - & & \\
3 & Occupational self-efficacy & 4.42 & 0.66 & .78 & -.07 & $.28^{* *}$ & - & \\
4 & Person-job fit & 3.69 & 0.66 & .82 & .00 & $.34^{* * *}$ & $.37^{* * *}$ & - \\
5 & Work engagement & 4.76 & 1.10 & .94 & .02 & $.40^{* * *}$ & $.32^{* * *}$ & $.67^{* * *}$ \\
\hline
\end{tabular}

Note. $N=312 .{ }^{* *} p<.01,{ }^{* * *} p<.001$

\section{Results}

Outliers can bias the results of multivariate analyses (Tabachnik \& Fidell, 2013), and we checked for multivariate outliers using Mahalanobis distance. Employing a $p$-value of $<.001$, we did not identify any outliers. We performed latent profile analysis (LPA) with MPlus 7 (Muthén \& Muthén, 2012) to identify groups of individuals with similar patterns of scores in perceived chance events and career decidedness. As an extension of and advantage over cluster analysis, LPA assumes that different probability distributions underlie a set of observed data on various variables. These assumed probability distributions are then used to assign observations to latent profiles (Vermunt \& Magidson, 2002). Because the perception of chance events may be confounded with an individual's locus of control (Bright, Pryor, \& Harpham, 2005), we included locus of control as a covariate in the LPA procedure. External locus of control was assessed with the 8-item (e.g., "When I get what I desire, there is most often luck involved in it") fatalistic externality subscale of the inventory for the measurement of self-efficacy and externality (FKK; Krampen, 1991). Answers were given on a scale ranging from 1 (very untrue) to 6 (very true).The alpha in the current sample was with .84 higher than the value of .75 obtained by the scale author. By controlling for locus of control, we are able to obtain a more valid evaluation of chance events in career development, independent of an individual's general tendency to perceive that uncontrollable events influence his or her life.

To address Research Question 1, we evaluated latent profile solutions in a stepwise procedure (for more details, see Nylund, Asparouhov, \& Muthén, 2007). We examined profiles with two to six groups and assessed the increase in model fit, parsimony, and theoretical interpretability of the model in each step. We used a series of criteria to choose the final model, as follows: (a) the sample-adjusted Bayesian information criterion (SABIC); (b) the bootstrapped likelihood ratio test (BLRT); (c) the number of cases in each profile, and (d) the posterior probabilities of each profile. The SABIC indicates the model with the best fit and fewest parameters when compared to a set of other nonhierarchical models. BLRT evaluates whether a model with $k$ profiles provides a better fit when compared to a model with $k$-1 profiles. A good latent profile solution is indicated by the lowest SABIC value, a significant BLRT $p$-value, the absence of profiles with a small number of cases, and a high probability of individuals belonging to the assigned latent profile.

We chose the five-profile solution because it showed the lowest SABIC value (SABIC $=1170.61$ ) and a significant BLRT value (BLRT $=16.75, p=.04$ ). One of the five extracted classes was small, with a posterior probability class size of 8.96 (7 cases, $2.2 \%$ ). The five profiles, however, all offered a distinct interpretation. The first profile, balanced scorers, included 159 (51\%) cases and was characterized by 
medium chance $(M=2.26, S D=.41)$ and mean level decidedness $(M=3.33, S D=.41)$. The second profile, undecided with mean chance, comprised 20 (6\%) individuals and was characterized by mean chance $(M$ $=1.99, S D=.38)$ and low decidedness $(M=1.89$, $S D=.37)$. The third profile, undecided with high chance, comprised only $7(2 \%)$ individuals. It was characterized by high chance $(M=3.17, S D=.24)$ and low decidedness $(M=2.06, S D=.30)$. The fourth profile, decided with chance, was composed of 51 $(16 \%)$ individuals and characterized by somewhat above average chance $(M=2.47, S D=.40)$ and high decidedness $(M=4.54, S D=.31)$. The fifth profile, decided without chance, described 75 (24\%) individuals and was characterized by below average chance $(M=1.90, S D=.47)$ and high decidedness $(M$ $=4.38, S D=.65$ ). Figure 1 depicts the standardized mean scores of perceived chance events and career decidedness for the five classes. Regarding Research Question 1, the results imply that quantitatively and qualitatively distinct profiles of perceived chance events and career decidedness exist among adolescents in vocational training.

To address Research Question 2, we used the BCH command (Bakk \& Vermunt, 2015) in Mplus. The BCH method employs weighted multiple group analysis to compare means using latent profiles as groups and Wald tests as difference tests. The $\mathrm{BCH}$ method performs well even when the variances of the distal variables differ across groups. All three motivational variables (occupational self-efficacy, person-job fit, and work engagement) significantly differed across the five latent profiles ( $p<.001$, see Table 2 , Figure 1 ). The balanced scorers group showed slightly below average values on all three motivational variables. This group displayed values that were more beneficial than the scores of the undecided with mean chance group but less favorable than the scores of the decided with chance and decided without chance groups. The undecided with mean chance group was characterized by the lowest motivational scores across all three motivational variables. The person- job fit and work engagement scores were significantly lower when compared to all other groups, and the occupational self-efficacy score was lower when compared with the decided with chance and decided without chance profiles. The undecided with high chance group showed low occupational self-efficacy scores but high person-job fit and work engagement scores. The levels of self-efficacy in this group were significantly lower than those in the decided without chance group, while the levels of person-job fit and work engagement were significantly higher than those in the balanced scorers and undecided with mean chance groups. The groups with the most favorable patterns of motivational variables were the decided with chance and decided without chance groups. These groups did not significantly differ between each other regarding the motivational variables but showed significantly higher values on all three motivational variables when compared to the undecided with mean chance group as seen in Table 2. Regarding Research Question 2, the results indicate that individuals with different chance/decidedness profiles differ in their work motivation. Post-hoc analysis yielded no significant differences in the latent profiles by gender or nationality (Swiss vs. foreign).

\section{Discussion}

Research has stressed the importance of chance events in career decision making and career development. Our study expanded this research by exploring the effects of chance events on career development. Specifically, we were interested in examining the relationship between chance events and work motivation among adolescents in vocational training; in other words, shortly after a major career transition. Moreover, we explored the relationship between perceived chance events and career decidedness, two frequently contrasted factors that influence career development. Extending beyond extant variable-centered studies, we applied a person-centered approach that explored profiles of perceived chance events and career decidedness. 
Table 2.

Latent Profile Size, Means, and Standard Deviations for Occupational Self-Efficacy, Person-Job Fit, and Work Engagement (Auxiliary Analyses)

\begin{tabular}{|c|c|c|c|c|c|c|c|c|}
\hline \multirow{2}{*}{\multicolumn{2}{|c|}{ Class }} & \multirow{3}{*}{$\begin{array}{l}n \\
145.76\end{array}$} & \multicolumn{2}{|c|}{$\begin{array}{l}\text { Occupational } \\
\text { self-efficacy }\end{array}$} & \multicolumn{2}{|c|}{ Person-job fit } & \multicolumn{2}{|c|}{ Work engagement } \\
\hline & & & $M$ & S.E. & $M$ & S.E. & $M$ & S.E. \\
\hline 1. & Balanced scorers (A) & & $4.30 \mathrm{E}$ & .06 & 3.52B, C, E & .06 & $4.37_{B, C, D, E}$ & .10 \\
\hline 2. & Undecided with mean chance (B) & 21.63 & $3.97 \mathrm{D}, \mathrm{E}$ & .20 & $3.01_{\mathrm{A}, \mathrm{C}, \mathrm{D}, \mathrm{E}}$ & .17 & $3.58 \mathrm{~A}, \mathrm{C}, \mathrm{D}, \mathrm{E}$ & .32 \\
\hline 3. & Undecided with high chance (C) & 8.96 & $4.15 \mathrm{E}$ & .17 & $4.01_{\mathrm{A}, \mathrm{B}}$ & .14 & $5.61_{\mathrm{A}, \mathrm{B}}$ & .49 \\
\hline 4. & Decided with chance (D) & 55.47 & $4.60_{\mathrm{B}}$ & .14 & $3.82_{\mathrm{B}}$ & .13 & $5.31_{\mathrm{A}, \mathrm{B}}$ & .18 \\
\hline \multirow[t]{2}{*}{5.} & Decided without chance (E) & 80.18 & $4.69_{\mathrm{A}, \mathrm{B}, \mathrm{C}}$ & .10 & $4.06_{\mathrm{A}, \mathrm{B}}$ & .10 & $5.29_{\mathrm{A}, \mathrm{B}}$ & .16 \\
\hline & Chi-square & & $24.42^{* * *}$ & & $44.28^{* * *}$ & & $54.44^{* * *}$ & \\
\hline
\end{tabular}

Note. All analyses were run using the BCH procedure in MPlus. The values for occupational self-efficacy, person-job fit, and work engagement are mean values for each profile. Data were available for $N=312 . n=$ latent profile size. Subscripts indicate profiles that are significantly different at $p<.05$. The chi-square (shown in the last row) indicates the significance of the overall difference test. ${ }^{* * *} p<.001$.

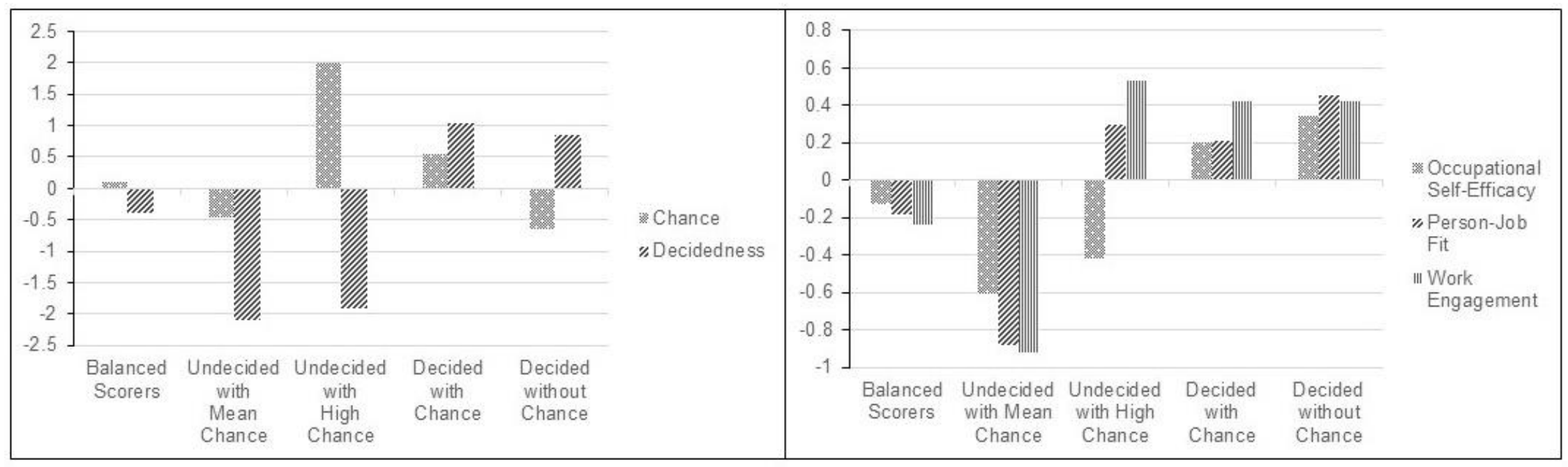

Figure 1. Left diagram represents the standardized means of latent profiles. Right diagram represents the standardized means of distal outcomes by latent profile. 


\section{Chance and Decidedness are not Opposites}

The first important result of our study is that perceived chance events and career decidedness are not opposites. On average, these factors were not significantly correlated, confirming previous findings (Hirschi, 2010). However, the applied profile analysis identified a range of qualitatively different profiles combining different levels of perceived chance events and decidedness. The results confirmed the utility of the person-centered approach because they showed that a nonsignificant correlation between chance and decidedness does not indicate that these factors are unrelated for all individuals. Our results showed that various combinations of levels of decidedness and perceived chance events exist. These profiles included balanced scorers, undecided with mean chance, undecided with high chance, decided with chance, and decided without chance. Our results suggested that some people experienced significant chance events while being decided regarding their careers. Other people, however, perceived a large influence of chance events while being undecided. No profile emerged with low levels of both perceived chance events and decidedness. This result suggests that if an individual has low decidedness, any career choice will be perceived as influenced by chance events. These findings have important implications for the theoretical understanding of chance events. Capitalizing on chance and being open to different possibilities is often depicted as the opposite of being decided on a specific career plan (Krumboltz, 2009). Our study advances this understanding and suggests that chance events have an influence on career development that can occur in conjuncture with or be independent from career decidedness and that the relationship varies across individuals.

\section{Chance/Decidedness Profiles and Work} Motivation

Our second aim was to explore how different profiles of chance and decidedness relate to different aspects of work motivation. Specifically, we investigated occupational self-efficacy beliefs, perceived person-job fit, and work engagement. The results showed that individuals with different profiles also significantly differed in their work motivation. Interestingly, the level of decidedness seems to be the most relevant factor in this regard. This is also mirrored in the low and nonsignificant bivariate correlations of chance events and our other study variables. Generally, individuals who reported above average decidedness also reported more work motivation, irrespective of their level of chance events. Adolescents who were decided with chance and those who were decided without chance did not significantly differ in the three motivational variables. However, both groups showed higher motivation in all three assessed aspects when compared to individuals with an undecided with mean chance profile. It is also noteworthy that only a very small minority of $2 \%$ reported a combination of low decidedness and high perceived chance. Interestingly, this group reported high values in person-job fit and work engagement, suggesting that these individuals do not suffer from negative work experiences. However, their occupational self-efficacy was comparatively low which implies that a sense of competence is harder to develop for adolescents who do not feel in control of their careers.

Combined, these results make an important contribution to the literature because they represent one of the rare instances in which the potential effects of chance events on career development outcomes were explored. Previous variable-centered studies have suggested that perceived chance events are related to finding a more congruent apprenticeship and higher satisfaction with that apprenticeship among Swiss adolescents (Hirschi, 2010). Among Israeli managers chance events were related to higher hierarchical position (Grimland et al., 2011). Our study extends these findings by applying a personcentered approach that takes into account that onaverage relationships between chance events and outcomes might not apply to some subpopulations. Moreover, to our knowledge, this study is the first to 
investigate work motivation as an outcome of career chance events. For the theoretical understanding of the role of chance events, our results suggest that perceiving a significant influence of chance events in one's previous career development does not impair work motivation in one's current job as long as one possesses a clear view of personal interests, preferences, and career goals (i.e., has a high level of career decidedness).

\section{Limitations and Future Research}

The data presented in the present study were based on a single source and assessed at one point in time. Therefore, it is possible that relations between variables might have been affected by common method bias. However, we accounted for a potential confounding common cause of perceived chance events and levels of career decidedness at the personality level by controlling for locus of control in the profile analysis.

Another limitation is that the undecided with high chance profile represented only $2 \%$ of the study participants. This may have compromised the statistical power of subsequent analyses involving this profile. However, including this profile was justified based on statistical and theoretical grounds. Overall, the assessed sample seems well suited to explore the research question of this study because the adolescents had recently undergone a major career transition for which both chance and decidedness can play pivotal roles. However, a developmental-contextual view suggests that career development should be understood as the dynamic interplay of person and context (Hartung et al., 2005). Older adults might view chance events differently because their main career developmental issues typically center around deepening their professional competence and updating their skills (Hall, 2002). This might promote a focus on stability and continuity that renders chance events to be perceived differently when compared to career transitions where chance may play a bigger role, as was the case in our study. The generalizability to other populations, such as older workers or university alumni, therefore remains to be established by future research.

Additionally, all sampled adolescents were at the end of their first year of vocational training. As such, selection and attrition effects likely occurred, and our results might not generalize to adolescents with very low work motivation who were not selected into a training position or who voluntarily or involuntarily quit during the first months of training. Finally, our study is a rare example of an exploration of the likely consequences of chance events in career development. More research is needed, however, to examine potential effects of chance events that were not taken into account in this study, for example, how chance events relate to perceived career success, turnover intentions, or organizational and occupational commitment.

\section{Implications for Practice}

For career counselors, our study offers several implications that address the use of the HLT in career interventions (Krumboltz, 2009; Krumboltz et al., 2013). Our results indicate that it is useful for career counselors to actively address issues of chance and happenstance in career development - particularly among adolescents who are dealing with relatively structured career transitions. Our study also supports the idea that chance events are often perceived as affecting career transition outcomes. Importantly, our results suggest that chance events have neither a good nor bad effect on work adjustment. This calls for counselors to approach the issue without value judgment on the merits or perils of chance and to foster open-mindedness among clients regarding this issue. As our results show, taking chance events into account in career interventions does not diminish the importance of more classical approaches that aim to foster career decidedness and career planning (e.g., Sampson, Lenz, Reardon, \& Peterson, 1999). In fact, our results suggest that a clear picture of personal interests, goals, and preferences is important for work motivation - regardless of the degree of perceived chance events. We would therefore suggest 
that counselors address chance events and simultaneously work with clients to clarify their vocational identity and develop meaningful career goals. In sum, we believe that our results suggest that the HLT is not an opposite but rather a complementary perspective to decision-focused counseling approaches.

\section{References}

Akkermans, J., Schaufeli, W. B., Brenninkmeijer, V., \& Blonk, R. W. B. (2013). The role of career competencies in the Job DemandsResources model. Journal of Vocational Behavior, 83(3), 356366. doi: 10.1016/j.jvb.2013.06.011

Bakk, Z., \& Vermunt, J. K. (2015). Robustness of stepwise latent class modeling with continuous distal outcomes. Structural Equation Modeling. doi: 10.1080/10705511.2014.955104

Bandura, A. (2001). Social cognitive theory: An agentic perspective. Annual Review of Psychology, 52, 1-26. doi: 10.1146/annurev.psych.52.1.1

Bright, J. E. H., Pryor, R. G. L., Chan, E. W. M., \& Rijanto, J. (2009). Chance events in career development: Influence, control and multiplicity. Journal of Vocational Behavior, 75(1), 14-25. doi: 10.1016/J.Jvb.2009.02.007

Bright, J. E. H., Pryor, R. G. L., \& Harpham, L. (2005). The role of chance events in career decision making. Journal of Vocational Behavior, 66(3), 561-576. doi: 10.1016/J.Jvb.2004.05.001

Bright, J. E. H., Pryor, R. G. L., Wilkenfeld, S., \& Earl, J. (2005). The role of social context and serendipitous events in career decision making. International Journal of Educational and Vocational Guidance, 5(1), 19-36. doi: 10.1007/s10775-0052123-6

Grimland, S., Vigoda-Gadot, E., \& Baruch, Y. (2011). Career attitudes and success of managers: the impact of chance event, protean, and traditional careers. The International Journal of Human Resource Management, 23(6), 1074-1094. doi: $10.1080 / 09585192.2011 .560884$

Hall, D. T. (2002). Careers in and out of organizations. Thousand Oaks: Sage Publications.

Hartung, P. J., Porfeli, E. J., \& Vondracek, F. W. (2005). Child vocational development: A review and reconsideration. Journal of Vocational Behavior, 66, 385-419. doi: 10.1016/j.jvb.2004.05.006

Hirschi, A. (2010). The role of chance events in the school-to-work transition: The influence of demographic, personality and career development variables. Journal of Vocational Behavior, 77(1), 39-49. doi: 10.1016/j.jvb.2010.02.002

Hirschi, A. (2012). Callings and work engagement: Moderated mediation model of work meaningfulness, occupational identity, and occupational self-efficacy. Journal of Counseling Psychology, 59(3), 479-485. doi: 10.1037/a0028949
Hirschi, A., \& Herrmann, A. (2013). Assessing difficulties in career decision making among Swiss adolescents with the German My Vocational Situation Scale. Swiss Journal of Psychology, 72(1), 33-42. doi: 10.1024/1421-0185/A000097

Holland, J. L., Daiger, D. C., \& Power, P. G. (1980). My Vocational Situation. Palo Alto, CA: Consulting Psychologists Press.

Holland, J. L., Gottfredson, D. C., \& Power, P. G. (1980). Some diagnostic scales for research in decision-making and personality - identity, information, and barriers. Journal of Personality and Social Psychology, 39(6), 1191-1200. doi: 10.1037/h0077731

Jörin, S., Stoll, F., Bergmann, C., \& Eder, F. (2003). EXPLORIX-das Werkzeug zur Berufswahl und Laufbahnplanung. Deutschsprachige Adaption und Weiterentwicklung des SelfDirected Search (SDS) nach John Holland. Test-Set Ausgabe Österreich, Verlag Hans Huber.

Krampen, G. (1991). Fragebogen zu Kompetenz- und Kontrollüberzeugungen (FKK) [Inventory for the Measurement of Self-Efficacy and Externality]. Göttingen: Hogrefe.

Krumboltz, J. D. (2009). The Happenstance Learning Theory. Journal of Career Assessment, 17(2), 135-154. doi: $10.1177 / 1069072708328861$

Krumboltz, J. D., Foley, P. F., \& Cotter, E. W. (2013). Applying the Happenstance Learning Theory to Involuntary Career Transitions. Career Development Quarterly, 61(1), 15-26. doi: Doi 10.1002/J.2161-0045.2013.00032.X

Mitchell, K. E., Levin, A. S., \& Krumboltz, J. D. (1999). Planned happenstance: Constructing unexpected career opportunities. Journal of Counseling and Development, 77, 115-124. doi: 10.1002/j.1556-6676.1999.tb02431.x

Muthén, L. K., \& Muthén, B. O. (2012). Mplus user's guide (7th ed.). Los Angeles, CA: Muthén \& Muthén.

Nylund, K. L., Asparouhov, T., \& Muthén, B. O. (2007). Deciding on the number of classes in latent class analysis and growth mixture modeling: A Monte Carlo simulation study. Structural Equation Modeling, 14(4), 535-569. doi: 10.1080/10705510701575396

Pinquart, M., Juang, L. P., \& Silbereisen, R. K. (2003). Self-efficacy and successful school-to-work transition: A longitudinal study. Journal of Vocational Behavior, 63(3), 329-346. doi: 10.1016/S0001-8791(02)00031-3

Rigotti, T., Schyns, B., \& Mohr, G. (2008). A short version of the Occupational Self-Efficacy Scale: Structural and construct validity across five countries. Journal of Career Assessment, 16(2), 238-255. doi: 10.1177/1069072707305763

Saks, A. M., \& Ashforth, B. E. (2002). Is job search related to employment quality? It all depends on the fit. Journal of Applied Psychology, 87(4), 646-654. doi: 10.1037//00219010.87.4.646

Sampson, J. P., Lenz, J. G., Reardon, R. C., \& Peterson, G. W. (1999). A cognitive information processing approach to employment problem solving and decision making. Career Development Quarterly, 48, 3-18. doi: 10.1002/j.2161-0045.1999.tb00271.x 
Schaufeli, W. B., Bakker, A. B., \& Salanova, M. (2006). The measurement of work engagement with a short questionnaire - A cross-national study. Educational and Psychological Measurement, 66(4), 701-716. doi: $10.1177 / 0013164405282471$

State Secretariat for Education Research and Innovation. (2014). Vocational and professional education in Switzerland 2014. Bern, Switzerland.

Tabachnik, B. G., \& Fidell, B. G. (2013). Using multivariate statistics. Boston, MA: Pearson.

Vermunt, J. K., \& Magidson, J. (2002). Latent class cluster analysis. In J. A. Hagenaars \& A. L. McCutcheon (Eds.), Applied latent class analysis (pp. 89-106). Cambridge, UK: Cambridge University Press.

Wang, M., \& Hanges, P. J. (2011). Latent Class Procedures: Applications to Organizational Research. Organizational Research Methods, 14(1), 24-31. doi: $10.1177 / 1094428110383988$

Williams, E. N., Soeprapto, E., Like, K., Touradji, P., Hess, S., \& Hill, C. E. (1998). Perceptions of serendipity: Career paths of prominent academic woman in counseling psychology. Journal of Counseling Psychology, 45(4), 379-389. doi: 10.1037/00220167.45.4.379 